\title{
Sustainable Maintenance of low level road network
}

\author{
Jan Mikolaj ${ }^{1, *}$, and Luboš Remek ${ }^{1}$ \\ ${ }^{1}$ Department of Construction Management, University of Zilina, Faculty of Civil Engineering, Zilina \\ 01008, Slovakia
}

\begin{abstract}
Main goal of Road Network Management System is to ensure safety and continuity of road traffic on road network with low intensity and lower technical requirements. This is achieved with pavement management system (main component of road network management system). Most countries developed custom Pavement management systems (PMS) based on deterministic or probabilistic approach. Local road administrators of low level road networks often lack the software equipment such as HDM4, RoSy, Exor, etc. These and similar PMS Most PMS, however effective, are often cumbersome, demanding in regard to energy, know-how and software equipment. The majority of local road administrators of rural road networks thus resort to non-effective reactive maintenance strategies. This article describes an easy to use method, based on predetermined maintenance repair \& rehabilitation standards. Secondly, a simple method, based on road user cost, is introduced that administrator can use to prepare a list of road section eligible for repair according to their repair priority.
\end{abstract}

\section{Sustainable maintenance of a road network}

The purpose of maintenance repairs and rehabilitation (MR\&R) of asphalt pavements is to extend the useful life of the pavement, maintain a smooth riding surface, and prevent water from entering the underlying soil. Limited manpower and resources have increased the importance of MR\&R for the service life of a pavement. To keep a pavement in the best possible condition, it is important to use an effective pavement management system. Basic PMS logical structure is depicted in Figure 1.

Pavement management system is a subsystem of asset management. It should ensure an adequate dividing of assigned funds from state budget and additional regional tax funds. These funds are very limited, thus, sustainability principles have to be implemented so that the road network can provide the road users with socio-economic benefits. These benefits elevate the living standards of the society, which, in turn, is then more prone to spending which means more taxation money. Previous sentence denotes that the relations form a cycle - sustainability cycle - which is depicted in Figure 2.

\footnotetext{
* Corresponding author: lubos.remek@,fstav.uniza.sk
} 


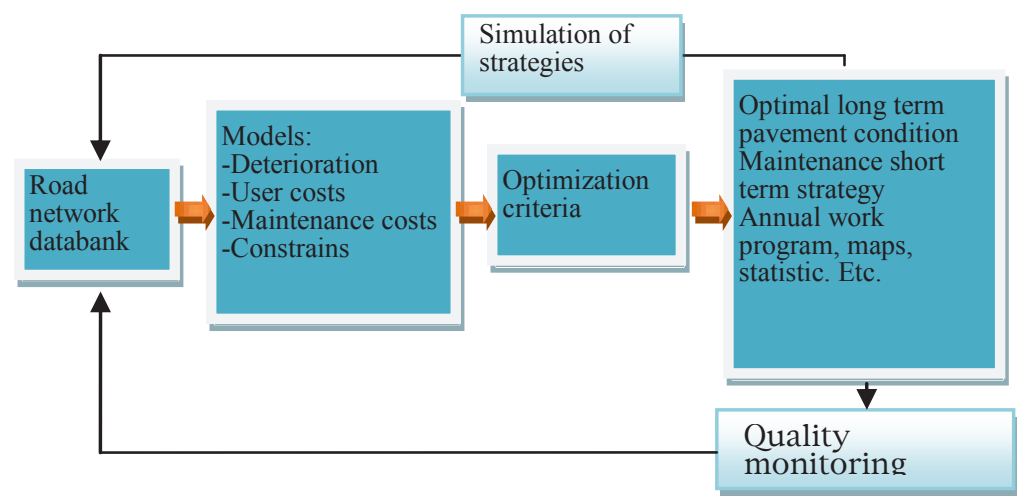

Fig. 1. Basic PMS scheme

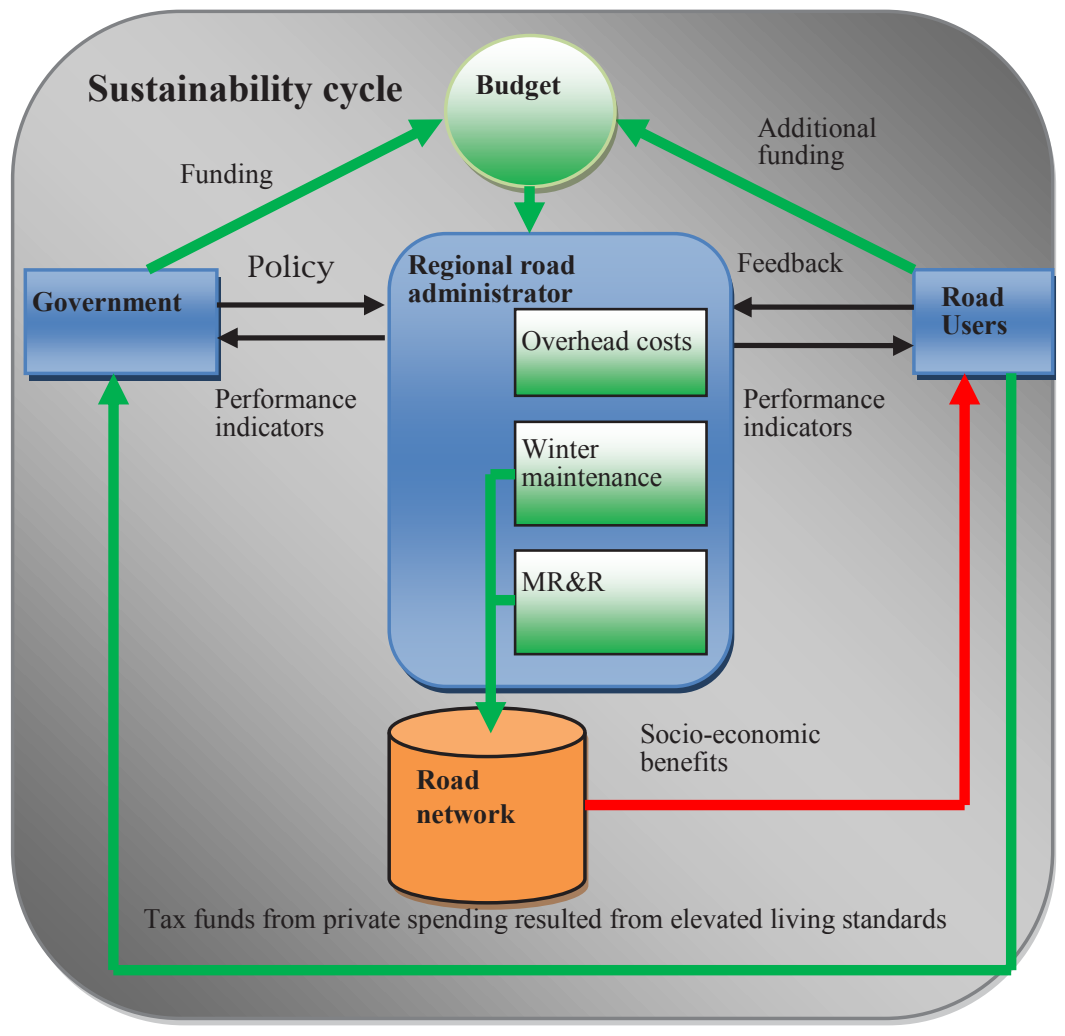

Fig. 2. Principle of sustainability in road administration

From the economical viewpoint, the sustainability principle means to balance the spend funds with generated funds which again can be spend, and so on, in an infinite cycle.

\section{Implementation of sustainable road maintenance}

Throughout European countries, aeging infrastructure problem is of growing concern, the ratio of low class roads in critical or poor condition and the amount of available resources of road administrators of these networks is beginning to reach critical levels. [1] A substite 
solution tocustom PMS may be needed to help road administrators of lower class roads in decision making. Since the rural roads are not usually surveyed systematically and their condition is not being tracked and used as an input for PMS, the municipal administrators of these roads rely on fixed MR\&R standard. The MR\&R procedures prescribed by fixed maintenance standard do not always correspond with the actual needs of the road conditions, nor do they take into account the budget possibilities of the road administrator; it is merely an empirically based schedule of pavement treatment works, which guarantees a good condition of the road throughout its whole life cycle. The downsides are obvious; the overall idea does not (mainly a high cost of this standard) correspond with the procedures described in asset management theory. Thus, road administration does not work effectively. The aim is to assess the possibilities of cheaper maintenance while ensuring fair pavement quality to the society. This also means that instead of having part of road network maintained in sub-optimal and part in over-optimal condition, more homogenous ride quality on whole network will be achieved.

As an experiment, 6 maintenance standards were created and applied to a $5 \mathrm{~km}$ long section of a low level road network. Figure 3 shows the costs of different variants. Following conclucions were drawn according to results obtained in the Highway Develompment and Management (HDM-4) software:

Variant 1- current maintenance variant - Very expensive variant appropriate only for road sections with heavy traffic load.

Variant 2- microsurfacing based variant - safe to use on all rural roads.

Variant 3- balanced cover layer exchange based variant - may be appropriate even for 3rd class roads with traffic load under 1000 AADT, especially, if they are not subject to excessive high load vehicles encumbrance.

Variant 4- one major cover layer exchange based variant - fairly safe to use on all rural roads.

Variant 5- one microsurface based variant - may be appropriate even for 3rd class roads with traffic load under 1000 AADT especially if they are not subject to excessive high load vehicles encumbrance.

Variant 6-basic variant - is appropriate only for 3rd class roads where the 1000 AADT limit is not exceed and are not subject to excessive high load vehicles encumbrance.

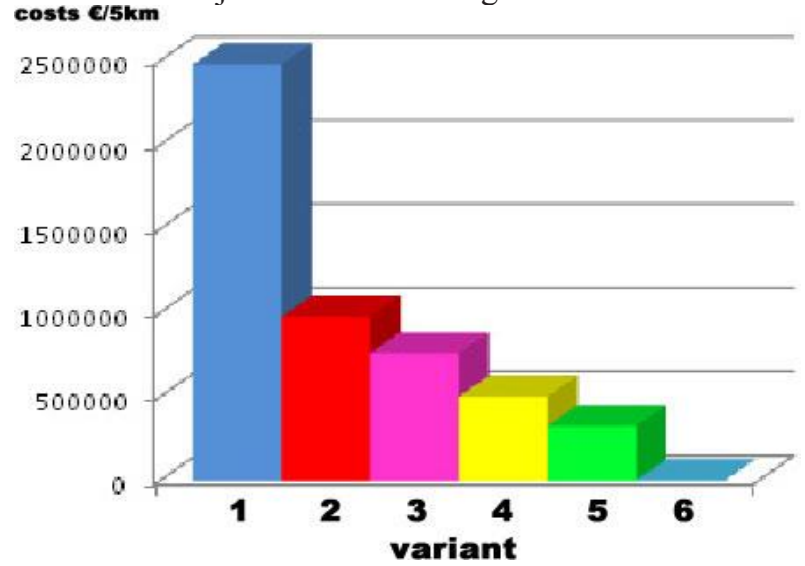

Fig. 3. Costs for selected variants 


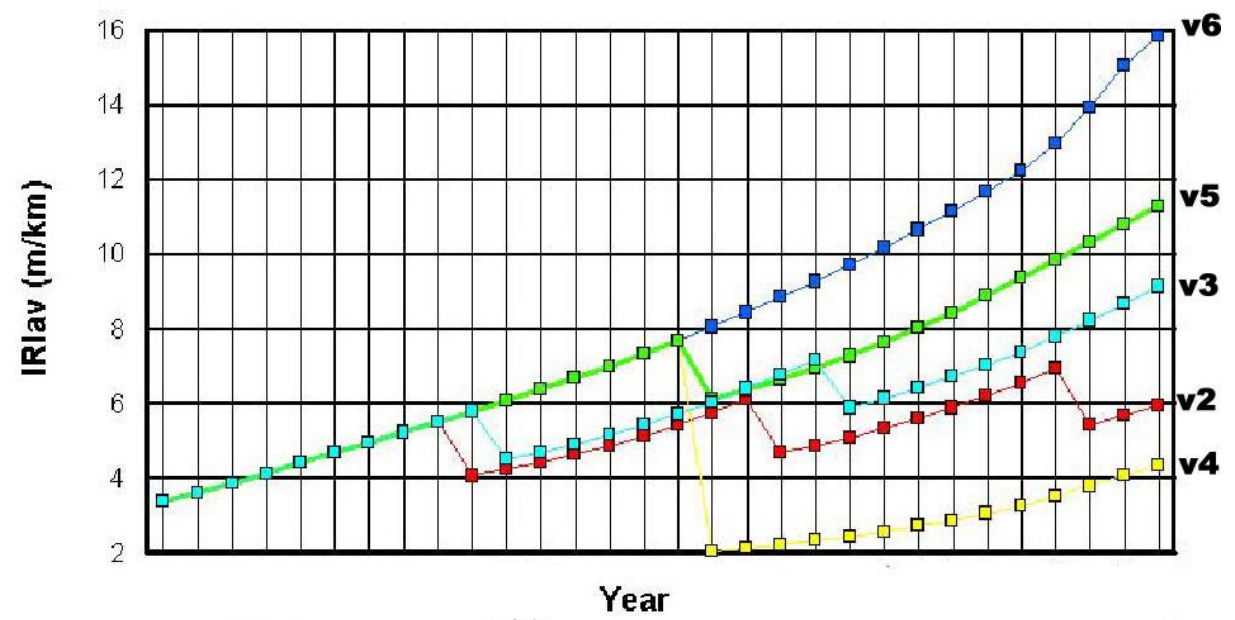

Fig. 4. Technical suitability of selected variants

The overall ranking of these variants are shown in Table 1 . Three criterions were taken into account - costs, technical suitability and economic effectiveness. As shown, variant 4, .i.e. one major overlay during the life cycle, ranks highest due even though scores average overall.

Table 1. Setting Word's margins.

\begin{tabular}{|c|c|c|c|c|c|c|}
\hline Viewpoint & $\underset{1}{\text { Variant }}$ & $\underset{2}{\text { Variant }}$ & $\underset{3}{\text { Variant }}$ & $\begin{array}{l}\text { Variant } \\
4\end{array}$ & $\underset{5}{\text { Variant }}$ & $\underset{6}{\text { Variant }}$ \\
\hline Cost & $6^{\text {th }}$ & $5^{\text {th }}$ & $4^{\text {th }}$ & $3^{\text {rd }}$ & $2^{\text {nd }}$ & $1^{\mathrm{st}}$ \\
\hline $\begin{array}{l}\text { Technical } \\
\text { suitability }\end{array}$ & $1^{\mathrm{st}}$ & $2^{\text {nd }}$ & $5^{\text {th }}$ & $3^{\mathrm{rd}}$ & $4^{\text {th }}$ & $6^{\text {th }}$ \\
\hline $\begin{array}{r}\text { Economic } \\
\text { effectiveness }\end{array}$ & $4^{\text {th }}$ & $5 \mathrm{t}^{\mathrm{h}}$ & $3^{\mathrm{rd}}$ & $2^{\text {nd }}$ & $1^{\mathrm{st}}$ & $6^{\text {th }}$ \\
\hline Overall & $3^{\text {rd }}$ & $4^{\text {th }}$ & $5^{\text {th }}$ & $1^{\text {st }}$ & $2^{\text {nd }}$ & $6^{\text {th }}$ \\
\hline
\end{tabular}

The road network is inhomogeneous and dynamic environment. The traffic load, condition of particular road section, volume of maintenance on this section in contrast to road administrator capabilities and others factors, all play an important part for choosing the appropriate MR\&R standard.

In an ideal case, road administrators would use analytical software to estimate which MR\&R standard should be used to maximize the socio-economic benefits for road users. For now, a complementary and easier method must be used. [2] The method should enable road administrators to quickly calculate socio-economic benefits for one vehicle, which, when combined with traffic survey, would enable them to calculate socio-economic benefits for the whole road section. It is important to note, that regional road administrators would have to implement a basic road condition survey system as some pavement data will be the input for such a system. 


\section{Simplified socio-economic cost calculation}

It is widely known that there are several factors influencing economical effectiveness of road maintenance and repair works; it is mainly the difference between technical parameters of maintained (do something) and un-maintained (do nothing) road, and costs of these works. Since MR\&R works do not influence the fixed technical parameters like geometrical alignments or width of communication; it is the surfacing parameters which changes are generating the benefits. It is assumed, that the main pavement condition parameter is the International Roughness Index (IRI) which usually is the main indicator of road surface condition. To prove this hypothesis, an experiment in HDM-4 was performedto show the influence IRI has on vehicle operating speed which change is the main indicator of road user benefits.

The HDM model [3] allows user to predict travel time costs and vehicle operating costs in relation to road parameters, pavement degradation levels, traffic intensity and unit costs. The model is mechanistic-empirical in origin. The mechanistic part of the model predicts forces opposing motion of the vehicle. The premise is that when the tractive force, empirically defined for particular vehicles, is in balance with forces opposing motion the vehicle drives with a constant speed, when those forces are greater the vehicle decelerated, when tractive force is greater the vehicle accelerates. This equilibrium is one of constrains limiting free speed of a vehicles, other being limiting curve speed and road speed limited by pavement roughness.

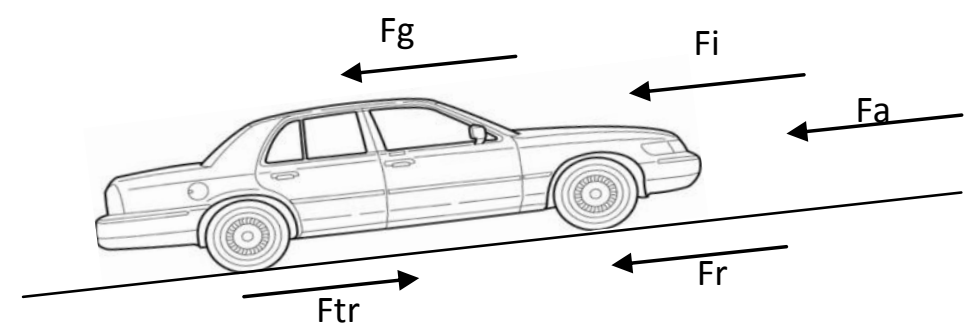

Fig. 5. Forces acting on a vehicle. Ftr - tractive force; Fa - aerodynamic drag resistance force; Fg gradient resistance force; $\mathrm{Fr}$ - rolling resistance force; $\mathrm{Fi}$ - inertial resistance force

Following is the calculation method for ascertaining listed forces oppressing motion. More info can be attained in the ISOHDM study.

$$
\mathrm{Fa}=0,5 \cdot \mathrm{r} \cdot \mathrm{CD} \cdot \mathrm{AF} \cdot \mathrm{vr}^{2}
$$

$\mathrm{Fa}$ aerodynamic drag resistance force [N]

$\mathrm{r} \quad$ air density $\left[\mathrm{kg} / \mathrm{m}^{3}\right]$

CD aerodynamic drag coefficient

AF vehicle frontal area $\left[\mathrm{m}^{2}\right]$

$\mathrm{vr}$ vehicle speed relative to wind $[\mathrm{m} / \mathrm{s}]$

$$
\mathrm{Fr}=\mathrm{M} \cdot \mathrm{g} \cdot \mathrm{CR}
$$

Fr rolling resistance force $[\mathrm{N}]$

$\mathrm{M}$ vehicle operating weight $[\mathrm{kg}]$

g gravitational acceleration $\left[\mathrm{m} / \mathrm{s}^{2}\right]$

$\mathrm{CR}$ rolling resistance coefficient

$$
F g=M \cdot g \cdot \sin (\theta)
$$


$\mathrm{Fg}$ gradient resistance force $[\mathrm{N}]$

$\theta \quad$ gradient $[\mathrm{rad}]$

$\mathrm{Fi}$ inertial resistance force $[\mathrm{N}]$

$$
\mathrm{Fi}=\mathrm{M}^{\prime} \cdot \mathrm{a}
$$

$\mathrm{M}^{\prime} \quad$ effective vehicle weight $[\mathrm{kg}]$

a acceleration $\left[\mathrm{m} / \mathrm{s}^{2}\right]$

Maximum traction force for individual vehicles can be usualy attained from wehicle manufacturer. Ftr is used for calculation of maxiumum vehicle speed (thus time costs) and road user costs. However, this simplified model doesn't include IRI, which is a significant factor when calculating road user costs. Therefore we present table 7 and chart on Figure 6 to see the maximal free speeds in relation to IRI for diferent vehicle categories; it can be seen that IRI doesn't influences the speed until 5-6 m. $\mathrm{km}^{-1}$. Additional free speeds to operating speed adjestments can be made according to [4].

Table 2. HDM model - Free speeds related to IRI

\begin{tabular}{ccccccc}
\hline IRI m.km-1 & $\begin{array}{c}\text { Small two- } \\
\text { axle rigid } \\
\text { truck }\end{array}$ & $\begin{array}{c}\text { Medium } \\
\text { two-axle } \\
\text { rigid truck }\end{array}$ & $\begin{array}{c}\text { Multi-axle } \\
\text { or Large } \\
\text { two-axle } \\
\text { bus }\end{array}$ & $\begin{array}{c}\text { Medium } \\
\text { passenger } \\
\text { cars }\end{array}$ & $\begin{array}{c}\text { Articulated } \\
\text { truck }\end{array}$ & $\begin{array}{c}\text { Multi-axle } \\
\text { rigid truck }\end{array}$ \\
\hline 1 & 99.25 & 88.02 & 114.23 & 123.43 & 90.04 & 91.24 \\
2 & 98.90 & 88.03 & 113.95 & 123.32 & 90.00 & 91.1 \\
3 & 98.26 & 87.80 & 113.53 & 122.74 & 89.93 & 90.94 \\
4 & 96.69 & 87.27 & 111.62 & 119.88 & 89.4 & 90.61 \\
5 & 93.34 & 85.93 & 104.04 & 112.05 & 86.55 & 89.26 \\
6 & 87.84 & 83.07 & 91.34 & 100.23 & 79.22 & 84.92 \\
7 & 80.88 & 78.41 & 79.31 & 88.28 & 69.98 & 77.29 \\
8 & 73.62 & 72.55 & 69.62 & 78.03 & 61.75 & 69.02 \\
9 & 66.85 & 66.45 & 61.95 & 69.65 & 55.02 & 61.75 \\
10 & 60.88 & 60.75 & 55.77 & 62.8 & 49.56 & 55.70 \\
\hline
\end{tabular}

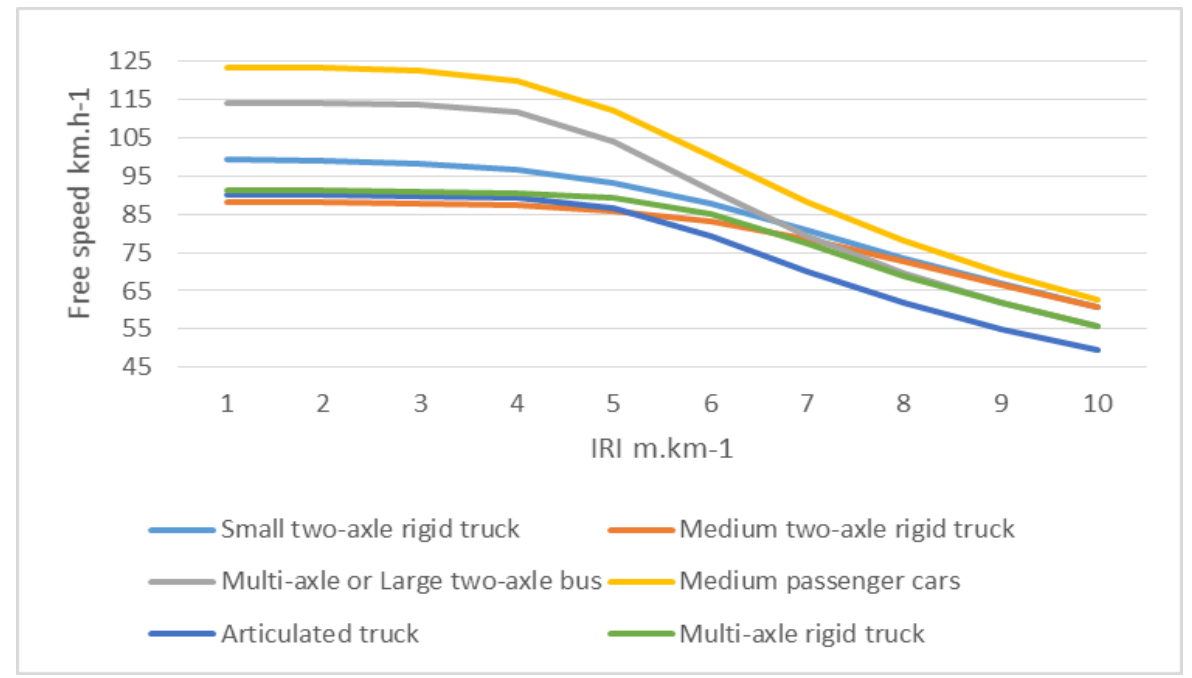

Fig. 6. HDM model - Free speeds related to IRI 
The empirical part of the model uses the resulting forces as a input to ascertain physical resources needs to operate a vehicle. Creating and maintaining tractive force to reach and maintain desired operating speed requires consumption of physical resources - fuel and lubricating oil. Additional resources are needed for operating the vehicle such as tyre wear, spare part consumption and maintenance labour requirement, these are more related to pavement conditions. Table 3 and Figure 7 can be used to estimate average vehicle operating costs relative to IRI.

Table 3. HDM model - Road user costs related to IRI in $€ / 1000$ vehiclekilometers

\begin{tabular}{cccccc}
\hline IRI m.km-1 & Fuel & Lubricating oil & Tyres & Spare parts & Maintenance \\
\hline 1 & 142.97 & 14.06 & 17.48 & 142.23 & 248.51 \\
2 & 144.04 & 14.09 & 17.78 & 142.24 & 248.52 \\
3 & 144.95 & 14.11 & 18.07 & 144.38 & 250.52 \\
4 & 144.81 & 14.11 & 18.25 & 163.86 & 268.03 \\
5 & 140.99 & 14.02 & 17.97 & 182.55 & 283.93 \\
6 & 133.00 & 13.83 & 17.10 & 198.63 & 297.02 \\
7 & 124.70 & 13.64 & 16.12 & 213.10 & 308.40 \\
8 & 118.93 & 13.50 & 15.27 & 226.97 & 318.96 \\
9 & 115.91 & 13.44 & 14.68 & 240.79 & 329.16 \\
10 & 114.99 & 13.41 & 14.29 & 254.80 & 339.19 \\
\hline
\end{tabular}

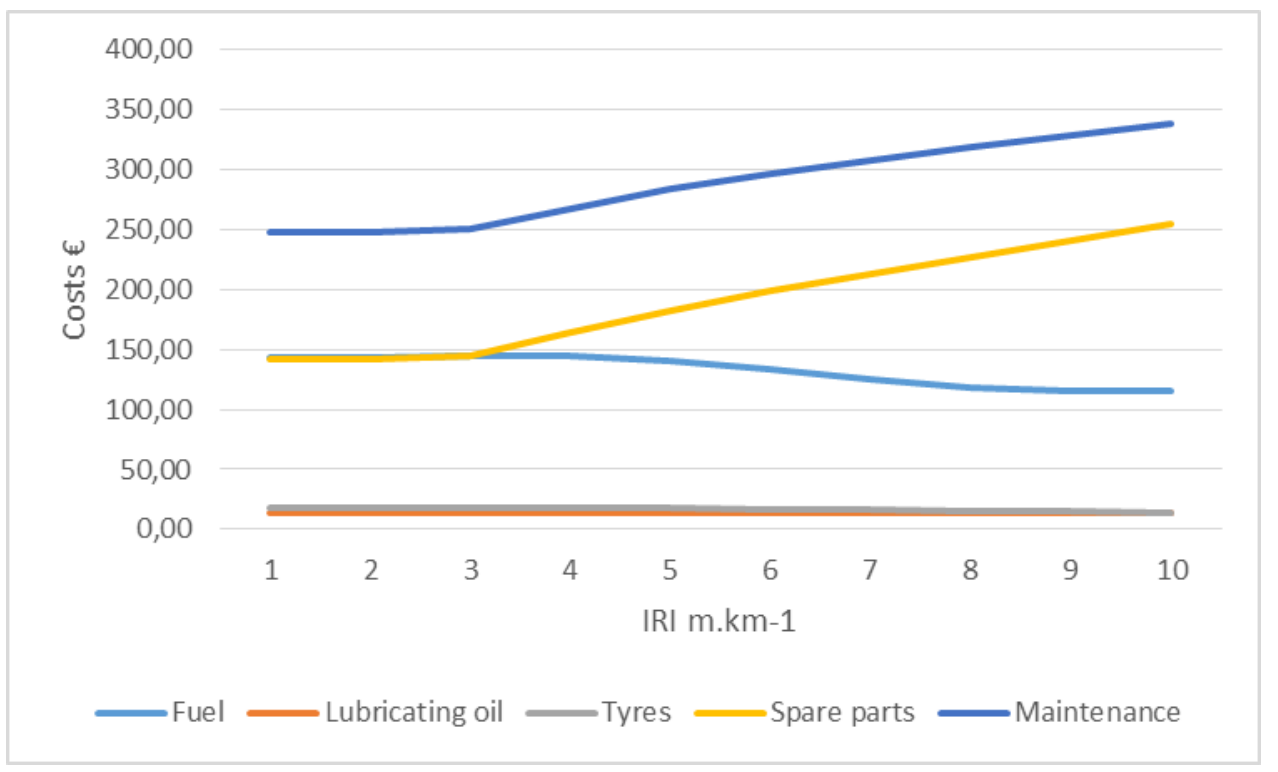

Fig. 7. HDM model - Vehicle operating costs related to IRI

The figure 7 shows that IRI of $3 \mathrm{~m} \cdot \mathrm{km}^{-1}$ sharply increases vehicle maintenance and spare parts consumption. Decrease in fuel consumption can be explained by the decrease of vehicle speed due to road damage. Influence of IRI on other vehicle operating costs seams negligible. 


\section{Conclusion}

Methods described in this article can be utilised by road network administrators in several ways. Easiest solution would be to choose from maintenance variants described in chapter 1 according to their ranking - preferring more expensive variants for roads with high AADT where higher pavement performance is needed and use less demanding variants for roads with lesser traffic intensity. If socio-economic costs are to be taken into account chapter 2 gives basic equations to calculate forces oppressing motion, which can be subsequently collated with traction forces of vehicles in traffic flow. This knowledge can be used in calculation of vehicle speed and road user costs for any generic cost benefit analysis procedures. This chapter also gives additional information on how longitudinal unevenness influences vehicle speed and vehicle operation costs, this can be used in conjunction with results from the forces oppressing motion method or independently.

With the result in mind, a conclusion was derived that a road administrator of a low level road network is capable to assess the importance of MR\&R action by a simple calculation where the IRI and traffic intensity of are the sole inputs for calculation of MR\&R action efficiency. He would not be able to calculate user cost directly, but he can collate road sections under his administrations and make a schedule of works with top priority MR\&R actions being on top. Using the methods in chapter 2 and equation 5, he can calculate prioritization index PI.

Where,

$$
\mathrm{PI}=\mathrm{AADT} \cdot\left(\operatorname{VOS}_{\mathrm{BA}}-\operatorname{VOS}_{\mathrm{AA}}\right)
$$

PI prioritization index,

VOSBA vehicle operating speed before action,

VOSAA vehicle operating speed after action.

Higher PI denotes a more effective MR\&R action. Provided we assume that vehicle operating speed is the main indicator of road user costs, the PI is proportional to user cost savings. Two main factors are neglected in this approach - the cost of MR\&R action and length of a road section. The premise is that length ads cost as well as benefits. This is a coarse statement but valid for road sections with length of about $0.2-5 \mathrm{~km}$.

This sound and easy method may be used as a basic decision making tool. Administrator still has to select technologically correct MR\&R technology, but it is a step to a proactive pavement management strategy.

\section{References}

1. L. Pepucha, L. Remek, Journal of Civil Engineering and Architecture, 8(4), 486-491 (2014)

2. Lubomír Pepucha, Lubos Remek, Acta logistica: international scientific journal, 1(1), 27-34 (2006)

3. World Road Association PIARC,The Highway Develompent and Management Series, ISBN2-84060-058-7, PARIS (2006)

4. Jan Mikolaj, Lubos Remek, TFoCE 111, 522-529 (2015) 